\title{
Preparation and properties of antibacterial sodium dehydroacetate/modified film
}

\author{
Fei FAN ${ }^{1}$ (D), Ning $\mathrm{LU}^{1}$, Shunchang $\mathrm{PU}^{1 \star}$, Fuxin YANG ${ }^{2}$
}

\begin{abstract}
Antibacterial polyethylene (PE) packaging films were prepared by combining granulation and casting with antibacterial agents sodium dehydroacetate (SD) and potassium sorbate (PS). The scanning electron microscopy (SEM) was used to characterize the structure of the films, and the effects of various additives on their physical, optical, microstructure, thermal stability, and antibacterial properties were investigated. The results show that when the SD: PS ratio is 2:1, the antibacterial film has higher tensile strength (14.71 MPa) than pure PE film. When the SD: PS ratio is 3:1, the water vapor transmission coefficient is the lowest, and The increase of SD concentration can result in good antibacterial activity against various microbes. The film has excellent physical and antibacterial properties, making it ideal for food packaging.
\end{abstract}

Keywords: antibacterial agents; films; properties; packaging materials.

Practical Application: Sodium dehydroacetate has an obvious antibacterial effect, by adding sodium dehydroacetate improves the physical and chemical properties of polyethylene film and enhances its antibacterial properties.

\section{Introduction}

As people pay more and more attention to health, to ensure the quality and safety of food, food packaging is becoming more and more important. At present, as preservatives are directly added to food for anti-corrosion, there are safety risks to human health (Ahari et al., 2021). Functional food packaging film can avoid direct contact between preservatives and food, inhibit the growth of microorganisms through the slow release of preservatives, and avoid the secondary pollution of packaged food (Costa et al., 2021; Lu et al., 2021; Priyadarshi \& Rhim, 2020). Food packaging has the characteristics of protecting food from foreign biological, chemical and physical factors, and maintaining the stability of food quality, which is of great significance to extend the shelf life of food.

Sodium dehydrogenate (SD; the first letter) is a healthy food antimicrobial, preservative authorised by the United Nations Food and Agriculture Organization (FAO) and the World Health Organization (WHO), Which is a new generation of alternative food preservatives after sodium benzoate, paraben and potassium sorbate (Yan et al., 2014). It is a broad-spectrum preservative that is unaffected by acidity or alkalinity. The antibacterial effect of $2 \% \mathrm{SD}$ antibacterial composite membrane was greater than that of potassium sorbate antibacterial composite membrane and sodium benzoate antibacterial composite membrane, because sodium dehydroacetate easily inhibits the normal growth of microorganisms such as bacteria, yeasts, moulds, and other microorganisms . It has been used in foods and drinks, and pharmaceutical formulations (Chen et al., 2016; He et al., 2019).

Potassium sorbate(PS; the first letter) as a common food additive has a good antiseptic and fresh-keeping effect in the food processing industry (Mohammadiani et al., 2021) . Its mechanism of action is to inhibit the activity of microbial dehydrogenase, at the same time, it combines with the sulfhydryl group in the enzyme system and destroys many main enzyme systems (Sun, 2018; Alzate et al., 2020). Its toxicity is far lower than other preservatives, so it is widely used at present.

Low-density polythene (LDPE) is a thermoplastic resin made by polymerizing ethylene. It is commonly used in the melt extrusion process, which produces one of the most popular packaging materials. LDPE has a low density and excellent mechanical properties, as well as excellent stress cracking and rigidity, as well as good heat resistance and chemical stability (Kumar et al., 2020; Yeh et al., 2015).

At present, due to the obvious antibacterial effect of potassium sorbate, there is no research on the synergistic antibacterial film of sodium dehydroacetate and potassium sorbate at home and abroad. Antibacterial polythene packaging films were developed in this study by incorporating various mass fractions of the Sodium dehydrogenate into potassium sorbate/LDPE. Following that, the optical properties, tensile strength, air permeability, microstructure, and other properties of the antibacterial films prepared were examined. The antibacterial activity of these films was evaluated on Escherichia coli and Staphylococcus aureus.

\section{Materials and methods}

\subsection{Materials}

Potassium sorbate(PS), food grade, Shanghai Pharmaceutical Group Chemical Reagent Co., Ltd. Sodium dehydroacetate (SD) food grade, Shanghai Chongming Biochemical Products Co., Ltd. Low density polyethylene (LDPE), Sinopec Jinshan Petrochemical Co., Ltd. 


\subsection{Experimental apparatus}

Torque rheometer: XSS-300, Shanghai Branch of a rubber and plastics Machinery Co., Ltd. Casting machine: LY-300, Shanghai Kechuang Rubber Machinery Co., Ltd. Limited company intelligent electronic Rally: XLW, Shandong Jinan Lan Electrical and Mechanical Technology Co., Ltd. Gas permeability tester: G2/132, Jinan Lan Guang Electrical and Mechanical Technology Co., Ltd. Water vapor permeability tester: PERMATR, the United States membrane Kang company. Transmittance / Haze Tester: GBB-B, Shanghai Jingke Instrument Company. TG NETZSCH209F3 Thermogravimetric analyzer , Netch Instruments Manufacturing Co., Ltd. Scanning Electron Microscope: S3400, Ion Sputter E-1010, Hitachi (Hitachi).

\subsection{Preparation of modified antimicrobial film}

According to the proportion(the modifier SD: PS ratio is 0:0, 1: 1, 2: 1, 3:1, 4: 1) of the experimental design (Table 1), adding the additives SD and PS to the LDPE resin at a mass fraction of $20 \%$, and the mixture was evenly combined before being extruded using a twin-screw extruder to create a modified antimicrobial LDPE masterbatch. Finally, $20 \%$ of the modified antimicrobial LDPE resin and $80 \%$ of the substrate LDPE resin were uniformly mixed with a single screw extrusion system via the casting machine casting film. The twin-screw equipment has 7 heating zones with the following temperatures: 1 area is $160{ }^{\circ} \mathrm{C}, 2$ area is $170^{\circ} \mathrm{C}, 5$ area is $160^{\circ} \mathrm{C}$, and the speed is set to $40 \mathrm{r} / \mathrm{min}$. Casting devices and a single screw 7 heating zones: 1 zone is $165^{\circ} \mathrm{C}$; 2 zones are $165^{\circ} \mathrm{C}$; 5 zones are $160^{\circ} \mathrm{C}$; speed is set to $60 \mathrm{r} / \mathrm{min}$; winding speed is $12 \mathrm{r} / \mathrm{min}$.

\subsection{Mechanical properties of the film}

Tensile strength (TS) is the highest tension under which a film can split. The TS of the film was determined using a smart electronic tensile tester and reference GB $1040-79$ at $25^{\circ} \mathrm{C}$ and $50 \% \mathrm{RH}$. With a cutting blade, the film was cut into thin strips $(15 \mathrm{~mm} \times 100 \mathrm{~mm})$, and its thickness was measured with a spiral micrometer. Loosen the upper and lower jaws of the instrument (30 $\mathrm{mm}$ wide $\times 40 \mathrm{~mm}$ long), insert the film into the clamping, set the pitch to $50 \mathrm{~mm}$, and the speed to $300 \mathrm{~mm} / \mathrm{min}$. Each sample was checked 5 times, with an average of (Rahmani et al., 2017; Faradilla et al., 2017). Tensile strength and elongation at break were determined using a Equation (1):

$$
T_{S}=\frac{F}{S}
$$

Table 1. Experimental design.

\begin{tabular}{cc}
\hline Membrane group & SD: PS (Ratio of mass fraction) \\
\hline A & $0: 0$ \\
B & $1: 1$ \\
C & $2: 1$ \\
D & $3: 1$ \\
E & $4: 1$ \\
\hline
\end{tabular}

Where: $\mathrm{T}_{S}$ hTensile strength, in units (MPa); $\mathrm{F}$ - the maximum force, unit $(\mathrm{N})$ of the specimen when it is broken; $\mathrm{S}-$ sample cross-sectional area, unit $\left(\mathrm{mm}^{2}\right)$.

\subsection{Optical properties of the film}

The film was placed on a standard whiteboard $\left(\mathrm{L}_{0}^{*}=94.46\right.$, $\left.a_{0}^{*}=-0.61, b_{0}^{*}=4.64\right)$. The color of the film was measured with a CR-400 color difference meter. Five samples were taken for each sample. $L^{*}, a^{*}$, and $b^{*}$. $L^{*}$ represents the range from black (0) to white (100), $\mathrm{a}^{*}$ represents the change from red $(+)$ to green $(-), b^{*}$ represents the change from yellow $(+)$ to blue $(-)$ (Benavides et al., 2012). The total color difference $\left(\Delta \mathrm{E}^{\star}\right)$ is calculated according to Equation (2)

$\Delta E^{*}=\left[\left(L_{0} *-L^{*}\right)^{2}+\left(a_{0} *-a *\right)^{2}+\left(b_{0} *-b *\right)^{2}\right]^{1 / 2}$

The film's transmittance and haze were measured using a WGT-S light transmittance/ haze tester (Nouri \& Nafchi, 2014). Preheat for 3 minutes after opening the instrument switch and the light hole, then put the film in the light hole and press the test button. Each sample is chosen for five different experiments.

\subsection{Water vapor transmission coefficient (WVP)}

At $37.8{ }^{\circ} \mathrm{C}$ and $100 \%$ relative humidity, the moisture permeability of the film was assessed using a water vapour transmission tester. A mould was used to cut the film into irregular 6-sided $\left(\right.$ area $50 \mathrm{~cm}^{2}$ ) shapes, and the thickness was measured with a spiral micrometre. The film samples were put in a sponge-permeable chamber, sealed with frictional grease on the edges, and tested three times per sample (Sogut \& Cakmak, 2020). The water vapour transmission coefficient (WVP) was determined using Equation (3):

$W V P=\frac{W V T R \times L}{\Delta P}$

Where WVP hwater vapor transmission coefficient, unit $\left(\times 10^{-14} \mathrm{~g} /(\mathrm{m} \cdot \mathrm{s} \cdot \mathrm{Pa})\right)$; WVTR-water vapor permeability measured by the instrument, in units $(\mathrm{g} /(\mathrm{m} \cdot \mathrm{d}))$; L-film thickness, unit (mm); $\Delta \mathrm{p}$-gas output pressure, $0.20 \mathrm{MPa}$

\subsection{Scanning Electron Microscopy (SEM)}

First, the film sample was cracked with liquid nitrogen and cut into $5 \mathrm{~mm} \times 3 \mathrm{~mm}$ pieces. It was adhered to a conductive adhesivecovered sample table, sprayed in a sputtering ion instrument for 30 seconds at a current of $20 \mathrm{~mA}$, and then examined using scanning electron microscopy (Li et al., 2021; Dashipour et al., 2015; Koc et al., 2020). The acceleration voltage is $5.0 \mathrm{kV}$.

\subsection{Thermogravimetric(TGA) analysis}

It is used to investigate the thermal stability of the antibacterial film. The specific operation was as follows: the sample material was weighed $5.0 \mathrm{mg}$, cut it into small pieces, and put it in a ceramic crucible for later use. Setting test temperature range: $40 \sim 600{ }^{\circ} \mathrm{C}$, temperature rising rate: $5{ }^{\circ} \mathrm{C} / \mathrm{min}$. During the 
experiment, to avoid thermal oxidation, 0.05 MPa nitrogen was used as the protective gas (Ghasemlou et al., 2011; Fernandes et al., 2020).

\subsection{Antibacterial test}

Cultivation of strains

E.coli and Staphylococcus aureus were cultured on a TSA plate at $37{ }^{\circ} \mathrm{C}$ for 18 hours, and then an appropriate amount of bacteria was picked and placed in a test tube containing $0.85 \%$ normal saline. The test tube was slightly shaken until the bacteria liquid was turbid, and the concentration was adjusted to $0.5 \times 10^{7} \mathrm{CFU} / \mathrm{mL}$, to be used.

\section{Determination of film antibacterial properties}

The film was weighed $0.27 \mathrm{~g}$ in a disposable petri dish and then sterilized under UV light for more than 2 hours (using sterile tweezers to flip the film during the sterilization process to make the sterilization more complete). The sterile film was placed in $10 \mathrm{~mL}$ of sterile TSB medium and soaked at $4{ }^{\circ} \mathrm{C}$ for 7 days. After the Petri dishes were sterilized that was added $15 \mathrm{~mL}$ of water agar per piece, and then let stand for solidification. Taking $1 \mathrm{~mL}$ of the bacterial solution and added it to $20 \mathrm{~mL}$ TSA medium, shaking well, pouring it into the plate, waiting for it to solidify, and using a sterile puncher to punch a hole with a diameter of $0.6 \mathrm{~mm}$ in the center of the plate coated with the bacterial solution (Deng et al., 2016; Mohamed et al., 2013). The $0.1 \mathrm{~mL}$ film soaking solution was sucked by pipette gun and transferred to the well of the plate for bacteria detection, refrigerated at $4{ }^{\circ} \mathrm{C}$ overnight, and placed in $37^{\circ} \mathrm{C}$ incubator for $24 \mathrm{~h}$ the next day. Three parallel groups were made for each sample, the diameter of inhibition zone was recorded and the average value was calculated.

\section{Result and discussion}

\subsection{Mechanical properties of different proportions of additive films}

Figure 1 depicts the tensile strength of films with varying additive proportions. With the addition of SD, the tensile strength of the film increased firstly and then decreased, and the elongation at break decreased. When the ratio of additive SD: PS was 1:1, the elongation at break of the film decreased slightly, when the ratio of additive SD: PS was more than 3:1, the elongation at break of the film decreased by $14.6 \%$. It may be that with the increase of SD mass, the probability of molecular contact increases and agglomeration occurs, which affects the fluidity of PE molecular chain; when the ratio of SD: PS was 2:1, tensile strength rose from 11.26 MPa to $14.70 \mathrm{MPa}$, which was $30.55 \%$ higher than group A. The additive increased the tensile strength of the film as well as its resistance when exposed to the external force. SD salts can combine with PS to form compounds that have a plasticizing effect on the films (Guiga et al., 2010), enhancing the stability of the LDPE resin's molecular structure and improving the mechanical properties of the films.

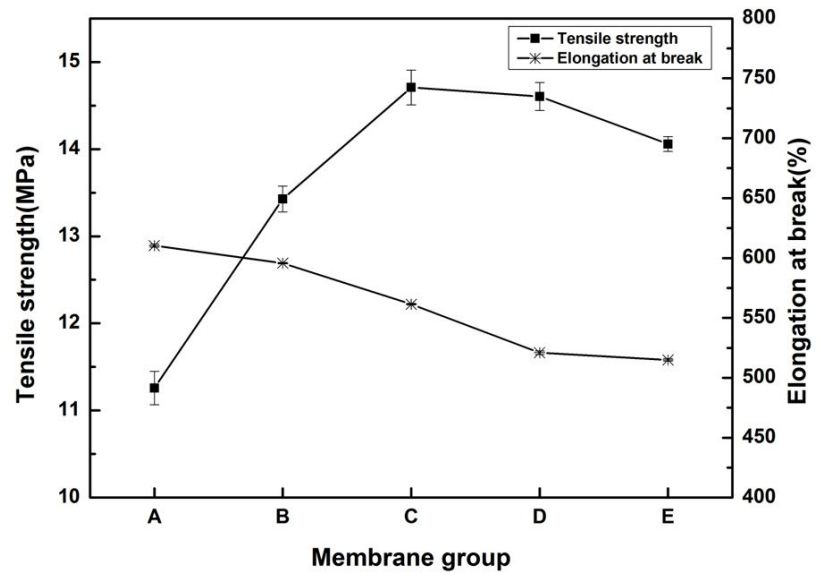

Figure 1. Effect of different proportions of additives on mechanical properties of films.

\subsection{The optical properties of different proportions of additive films}

The transparency of film is one of the important characteristics of food packaging. Transparent film can make consumers see the packaged products. The effect of additives on the colour and optical properties of the film is shown in Table 2. The film's transmittance was reduced after the additive was added, the minimum value was $62.9 \%$, which was $26.18 \%$ lower than that of the A category, and the haze transition was gentler, when the mass ratio of additive SD: PS is less than 2:1, implying that the additive was compatible with the PE resin molecule. However, the haze and light transmittance changed obviously with increasing the content of modifier SD, especially the haze of group E had increased to $6.93 \%$. This phenomenon may be caused by the addition of SD, which destroys the crystal zone between molecules, forms agglomerated particles, hinders the transmission light, and affects the light transmittance and haze of the film. The addition of the additive to the PE relative to the control group affected the scattering of light in the polymer matrix (Benavides et al., 2012), according to the value of $\Delta \mathrm{E}^{*}$, and the clarity of the composite film was increased to decrease the value of $\Delta \mathrm{E}^{*}$.

\subsection{Moisture permeability coefficient of films with different proportion of additives}

Figure 2 depicts the influence of the additive on the water vapour transmission coefficient (WVP) of the composite films. After addition of the additive, the water vapour permeability coefficients of groups B and C is lower than those of group A. Since the ratio of SD to PS is less than 3:1 or greater than 1:1, the effect of additives on the molecular structure of PE resin is minimal, as is the change in the water vapour transmission coefficient. The plasticizing effect of an appropriate proportion of additives increases the stability of the molecular structure of the film, and the lengthening of the intermolecular path leads to a decrease in the water vapor transmission coefficient. 
Table 2. Effects of different proportions of additives on the optical properties of films.

\begin{tabular}{cccc}
\hline $\begin{array}{c}\text { Membrane } \\
\text { group }\end{array}$ & $\begin{array}{c}\text { Transmittance } \\
(\%)\end{array}$ & $\begin{array}{c}\text { Haze } \\
(\%)\end{array}$ & $\begin{array}{c}\text { Colour } \\
\text { difference }\left(\Delta \mathrm{E}^{\star}\right)\end{array}$ \\
\hline A & $89.08 \pm 0.898$ & $2.384 \pm 0.116$ & $1.693 \pm 0.084$ \\
B & $87.04 \pm 1.093$ & $2.410 \pm 0.340$ & $1.417 \pm 0.022$ \\
C & $77.76 \pm 1.977$ & $3.684 \pm 0.226$ & $1.303 \pm 0.090$ \\
D & $67.04 \pm 1.451$ & $5.728 \pm 0.230$ & $1.194 \pm 0.087$ \\
E & $62.90 \pm 0.729$ & $6.930 \pm 0.264$ & $1.271 \pm 0.016$ \\
\hline
\end{tabular}

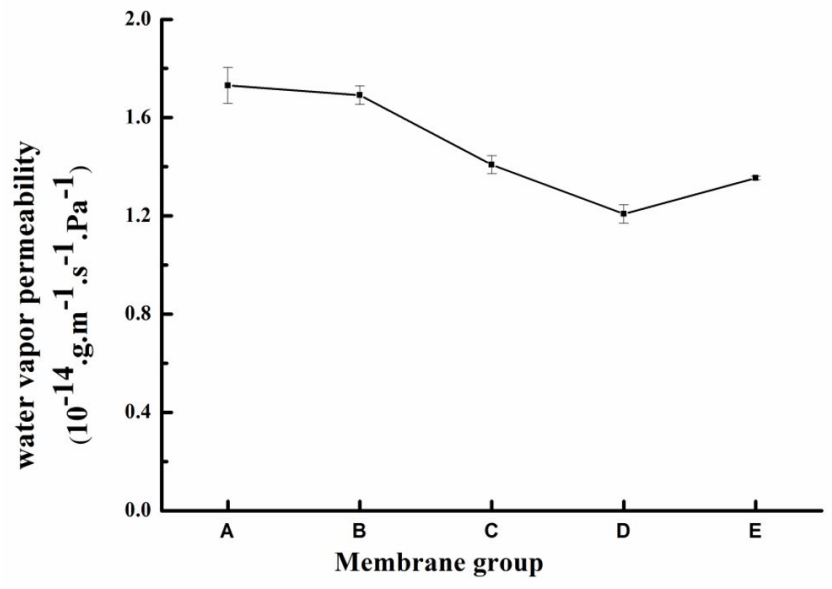

Figure 2. Effect of different proportion additives on water vapor transmission coefficient of films.

\subsection{Microscopic analysis of the films with different proportions of additives}

As shown in Figure 3, the additive has a noticeable influence on the compactness of the composite film structure. Small stripes were visible in the cross-section of group A. The cross-section of the film became thick and smooth as the SD/PS ratio rose, while the cross-section of the $\mathrm{D}$ and $\mathrm{E}$ films became slightly rough. The findings indicate that the addition of SD is very consistent with the polymer's chemical bond and improves the structure's stability.

\subsection{TGA analysis of the films with different proportions of additives}

As shown in Figure 4, the TGA analysis curve reflects the influence of different content of modifier on the thermal stability of the film. The mass loss of the five kinds of films can be divided into three stages. The first stage occurs between $0^{\circ} \mathrm{C}$ and $300^{\circ} \mathrm{C}$, and all the films have no mass loss. Because the structure of polyethylene resin is stable at this stage, the decomposition temperature of the film has not yet reached. The second stage occurs between $300{ }^{\circ} \mathrm{C}$ and $500{ }^{\circ} \mathrm{C}$, and the film begins to decompose rapidly. When the temperature is $425^{\circ} \mathrm{C}$, the mass loss of group $\mathrm{E}$ is $13.45 \%$, groups $\mathrm{B}$ and $\mathrm{C}$ begin to decompose at $430^{\circ} \mathrm{C}$, which indicates that the thermal stability of the film can be improved by appropriate amount of modifier. The third stage occurs when the temperature is higher than $500{ }^{\circ} \mathrm{C}$, and the weight loss of the films tends to be stable. From the second stage, it can be seen that the film of groups B and C can improve the thermal stability of the film, and the addition of too much modifier SD will affect the crystal structure of the film, resulting in a decrease in the thermal stability of the film.
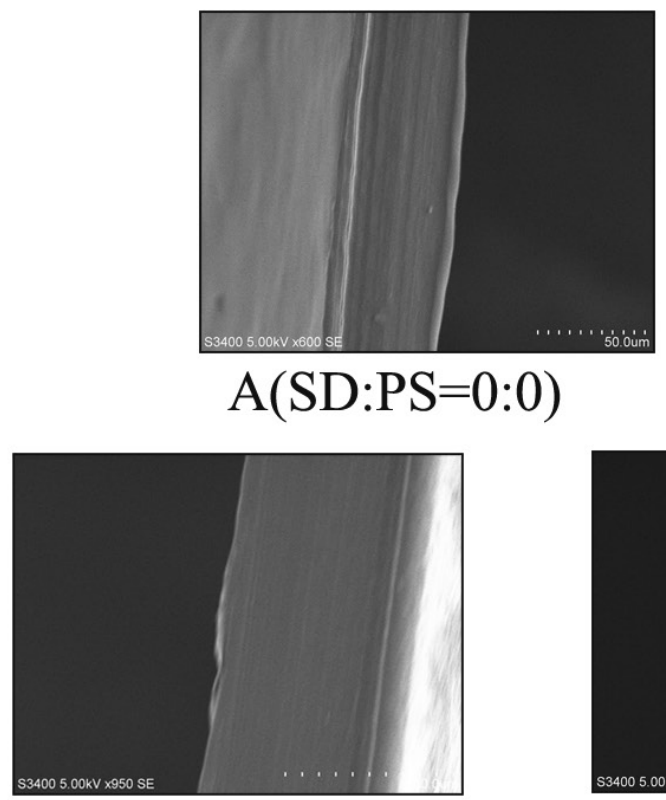

$\mathrm{C}(\mathrm{SD}: \mathrm{PS}=2: 1)$

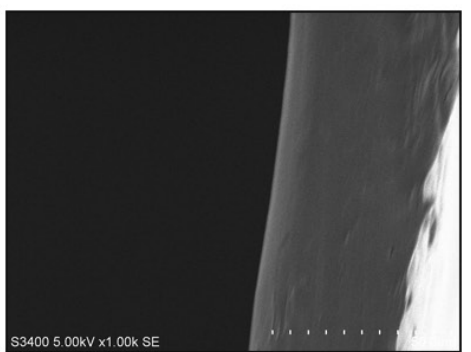

$\mathrm{D}(\mathrm{SD}: \mathrm{PS}=3: 1)$

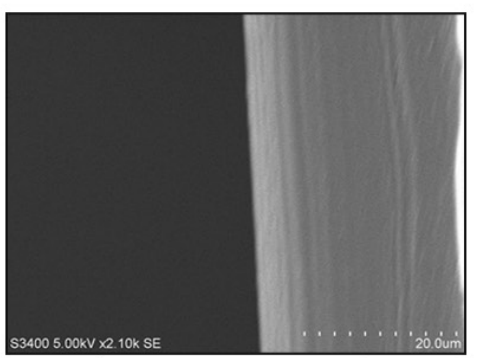

$\mathrm{B}(\mathrm{SD}: \mathrm{PS}=1: 1)$

Figure 3. Effect of different proportion additives on microstructure of films. 


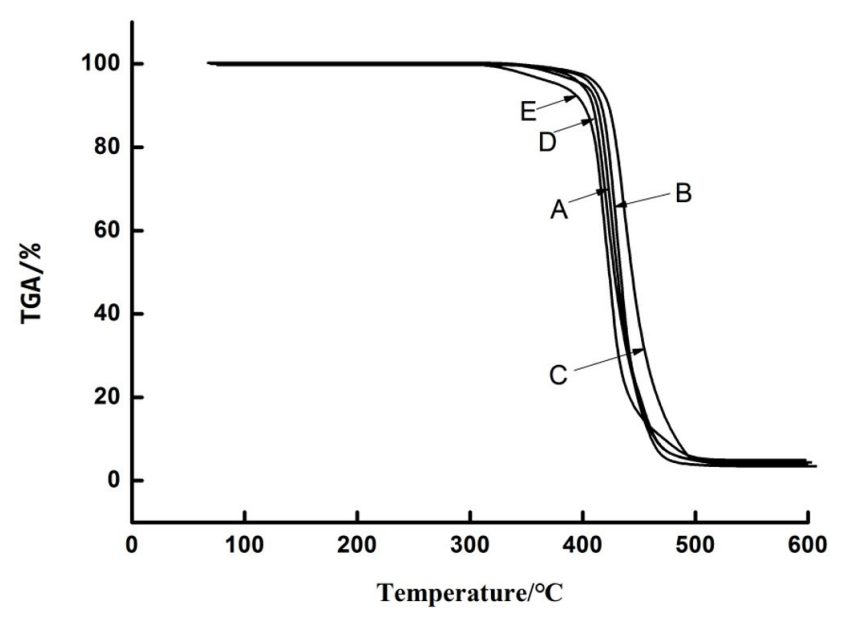

Figure 4. TGA curves of additives with different proportions of films.

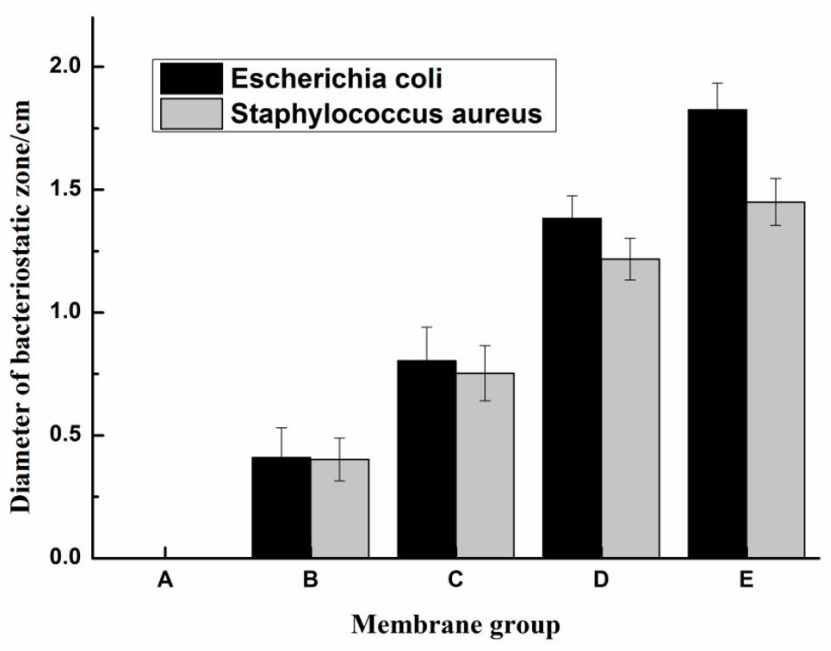

Figure 5. Bacteriostatic effect of different proportion additive films.

\subsection{Antibacterial properties of the films with different proportions of additives}

The antibacterial test results in Figure 5 demonstrate that the diameter of inhibition zone of polyethylene film without modifier in the control group is 0 , but the inhibition zone of polyethylene film in group B is $0.410 \mathrm{~cm}$ and $0.402 \mathrm{~cm}$ respectively, indicating that every film in the experimental group has an obvious inhibition effect on Escherichia coli and Staphylococcus aureus. In the experimental group, the inhibitory effect of the films on Escherichia coli were stronger than that on Staphylococcus aureus. Because Escherichia coli was more sensitive to antimicrobial agents, SD might has a stronger inhibitory effect on Escherichia coli (Seydim \& Sarikus, 2006). The diameter of the bacteriostatic circle of group C and group D films was higher than that of other groups, and the maximum increase of the inhibition zone in group D was $0.579 \mathrm{~cm}$, indicating that SD and PS were largely dispersed in the film system when they were mixed in polyethylene resin, and their synergistic effect further enhanced the antibacterial properties of the film. Therefore, the synergistic effect of SD and PS modifiers can significantly improve the antibacterial effect of the film.

\section{Conclusions}

The melt-blending method was used in this study to adjust the PE resin. Compared with the pure PE film, the modified polyethylene film is added with suitable sodium dehydroacetate, which has a smooth cross-section microstructure, good heat resistance, and added Sodium dehydrogenate increases the tensile strength of the film, reduces the elongation at break of the film, affects its optical properties, and reduces the water vapor transmission coefficient of the film. As the ratio of SD:PS increases, the modified antibacterial film has a certain antibacterial effect on the microorganism. The modified film by sodium dehydroacetate has excellent packaging properties and exhibits certain antibacterial properties, it is a good new-type food packaging material.

\section{Acknowledgements}

The work described in this paper was fully supported by a grant from the Anhui University Natural Science Research Project (KJ2020a0767), Bozhou Key Laboratory of Medicinal and Edible Homology Functional Food (Bozhou University), and Discipline team of food processing technology (BYZXKTD201802). Authors acknowledge financial and experimental support by Bozhou University and Dr. Fuxin Yang for preparation of polyethylene film.

\section{References}

Ahari, H., Anvar, A. A., Ataee, M., \& Naeimabadi, M. (2021). Employing nanosilver, nanocopper, and nanoclays in food packaging production: a systematic review. Coatings, 11(5), 509. http://dx.doi.org/10.3390/ coatings11050509.

Alzate, P., Gerschenson, L., \& Flores, S. (2020). Ultrasound application for production of nano-structured particles from esterified starches to retain potassium sorbate. Carbohydrate Polymers, 247, 116759. http://dx.doi.org/10.1016/j.carbpol.2020.116759. PMid:32829872.

Benavides, S., Villalobos-carvajal, R., \& Reyes, J. E. (2012). Physical, mechanical and antibact- erial properties of alginate film: effect of the crosslinking degree and oregano essential oil concentration. Journal of Food Engineering, 110(2), 232-239. http://dx.doi.org/10.1016/j. jfoodeng.2011.05.023.

Chen, J. Y., Yang, F. X., We, I. L. J., Du, Y. P., \& Wang, H. L. (2016). Preparation and properties of polyvinyl alcohol modified non-woven antibacterial composite membrane. Food Machinery, 12, 124-127.

Costa, S. M., Ferreira, D. P., Teixeira, P., Ballesteros, L. F., Teixeira, J. A., \& Fangueiro, R. (2021). Active natural-based films for food packaging applications: the combined effect of chitosan and nanocellulose. International Journal of Biological Macromolecules, 177, 241-251. http://dx.doi.org/10.1016/j.ijbiomac.2021.02.105. PMid:33631258.

Dashipour, A., Razavilar, V., Hosseini, H., Shojaee-Aliabadi, S., German, J. B., Ghanati, K., Khakpour, M., \& Khaksar, R. (2015). Antioxidant and antimicrobial carboxy- methyl cellulose films containing Zataria multiflora essential oil. International Journal of Biological Macromolecules, 72, 606-613. http://dx.doi.org/10.1016/j. ijbiomac.2014.09.006. PMid:25220790. 
Deng, T. C., Zhu, M. J., Du, S. X., \& Yao, Y. F. (2016). Comparative study of bacteriostatic circle method in bacteriostatic test. Food Industries, 37(11), 122-125.

Faradilla, R., Lee, G., Roberts, J., Martens, P., Stenzel, M., \& Arcot, J. (2017). Effect of glycerol, nanoclay and graphene oxide on physicochemical properties of biodegradable nanocellulose plastic sourced from banana pseudo-stem. Cellulose, 25(1), 399-416. http:// dx.doi.org/10.1007/s10570-017-1537-x.

Fernandes, L. M., Guimarães, J. T., Silva, R., Rocha, R. S., Coutinho, N. M., Balthazar, C. F., Calvalcanti, R. N., Piler, C. W., Pimentel, T. C., Cucinelli, R. P. No., Tavares, M. I. B., Esmerino, E. R., Freitas, M. Q., Silva, M. C., \& Cruz, A. G. (2020). Whey protein films added with galactooligosaccharide and xylooligosaccharide. Food Hydrocolloids, 104, 105755. http://dx.doi.org/10.1016/j.foodhyd.2020.105755.

Ghasemlou, M., Khodaiyan, F., \& Oromiehie, A. (2011). Physical, mechanical, barrier, and thermal properties of polyol-plasticized biodegradable edible film made from kefiran. Carbohydrate Polymers, 84(1), 477-483. http://dx.doi.org/10.1016/j.carbpol.2010.12.010.

Guiga, W., Swesi, Y., Galland, S., Peyrol, E., Degraeve, P., \& Sebti, I. (2010). Innovative multilayer antimicrobial films made with Nisaplin or nisin and cellulosic ethers: Physico-chemical characterization, bioactivity and nisin desorption kinetic. Innovative Food Science \& Emerging Technologies, 11(2), 352-360. http://dx.doi.org/10.1016/j. ifset.2010.01.008.

He, L., Lan, W., Ahmed, S., Qin, W., \& Liu, Y. (2019). Electrospun polyvinyl alcohol film containing pomegranate peel extract and sodium dehydroacetate for use as food packaging. Food Packaging and Shelf Life, 22, 100390. http://dx.doi.org/10.1016/j.fpsl.2019.100390.

Koc, B., Akyuz, L., Cakmak, Y. S., Sargin, I., Salaberria, A. M., Labidi, J., Ilk, S., Cekic, F. O., Akata, I., \& Kaya, M. (2020). Production and characterization of chitosan-fungal extract films. Food Bioscience, 35, 100545. http://dx.doi.org/10.1016/j.fbio.2020.100545.

Kumar, V., Gulati, K., Lal, S., \& Arora, S. (2020). Effect of gamma irradiation on tensile and thermal properties of poplar wood flour-linear low density polyethylene composites. Radiation Physics and Chemistry, 174, 108922. http://dx.doi.org/10.1016/j.radphyschem.2020.108922.

Li, Y., Ren, J. Z., Zhang, G. Q., \& Li, X. Z. (2021). High-barrier and antibacterial films based on PET/SiOx for food packaging applications. Food Science and Technology, 41(3), 763-767. http:// dx.doi.org/10.1590/fst.37720.

Lu, W. W., Cui, R., Zhu, B. F., Qin, Y. Y., Cheng, G. G., Li, Y., \& Yuan, M. L. (2021). Influence of clove essential oil immobilized in mesoporous silica nanoparticles on the functional properties of poly (lactic acid) biocomposite food packaging film. Journal of
Materials Research and Technology., 11, 1152-1161. http://dx.doi. org/10.1016/j.jmrt.2021.01.098.

Mohamed, C., Clementine, K. A., Didier, M. L., Gérard, L., \& Noëlle, D. M. (2013). Antimicrobial and physical properties of edible chitosan films enhanced by lactoperoxidase system. Food Hydrocolloids, 30(2), 576-580. http://dx.doi.org/10.1016/j.foodhyd.2012.07.018.

Mohammadiani, E., Aliakbarlu, J., Ownagh, A., \& Kaboudari, A. (2021). Antifungal interactions of Persian shallot (Allium hirtifolium) extracts and potassium sorbate against Aspergillus flavus and Penicillium citrinum. Flavour and Fragrance Journal, 36(3), 332-338. http:// dx.doi.org/10.1002/ffj.3645.

Nouri, L., \& Nafchi, A. M. (2014). Antibacterial, mechanical, and barrier properties of sago starch film incorporated with betel leaves extract. International Journal of Biological Macromolecules, 66, 254-259. http://dx.doi.org/10.1016/j.ijbiomac.2014.02.044. PMid:24582935.

Priyadarshi, R., \& Rhim, J. W. (2020). Chitosan-based biodegradable functional films for food packaging applications. Innovative Food Science \& Emerging Technologies, 62, 102346. http://dx.doi. org/10.1016/j.ifset.2020.102346.

Rahmani, B., Hosseini, H., Khani, M., Farhoodi, M., Honarvar, Z., Feizollahi, E., Shokri, B., \& Shojaee-Aliabadi, S. (2017). Development and characterisation of chitosan or alginate-coated low density polyethylene films containing Satureja hortensis extract. International Journal of Biological Macromolecules, 105(1), 121-130. http://dx.doi. org/10.1016/j.ijbiomac.2017.07.002. PMid:28684349.

Seydim, A. C., \& Sarikus, G. (2006). Antimicrobial activity of whey protein based edible films incorporated with oregano, rosemary and garlic essential oils. Food Research International, 39(5), 639-644. http://dx.doi.org/10.1016/j.foodres.2006.01.013.

Sogut, A., \& Cakmak, H. (2020). Utilization of carrot (Daucus carota L.) fiber as a filler for chitosan based films. Food Hydrocolloids, 106, 105861. http://dx.doi.org/10.1016/j.foodhyd.2020.105861.

Sun, M. (2018). Detection of 8 common preservatives and 2 sweeteners in beverages by RP-HPLC method. Food Industries, 39(7), 323-326.

Yan, Q., Zhang, J., Dong, H. Z., Hou, H. X., \& Guo, P. (2014). Properties and antimicrobial activities of starch-sodium alginate composite films incorporated with sodium dehydroacetate or rosemary extract. Journal of Applied Polymer Science, 127(03), 1951-1958. http://dx.doi. org/10.1002/app.37570.

Yeh, C. L., Nikolic, M. A. L., Gomes, B., Gauthier, E., Laycock, B., Halley, P., Bottle, S. E., \& Colwell, J. W. (2015). The effect of common agrichemicals on the environmental stability of polyethylene films. Polymer Degradation \& Stability, 122, 53-60. http://dx.doi. org/10.1016/j.polymdegradstab.2015.06.007. 